http://jmscr.igmpublication.org/home/

ISSN (e)-2347-176x ISSN (p) 2455-0450

crossref DOI: https://dx.doi.org/10.18535/jmscr/v8i5.74

Journal Of Medical Science And Clinical Research

\title{
Emerging Kawasaki Disease (KD) in Covid 19 Era: 3 Cases in a Month
}

\author{
Authors \\ Dr Sunil Kumar Agarwalla ${ }^{1}$, Dr Dibya Ranjan Panda ${ }^{2}$ \\ ${ }^{1}$ Associate Professor, Dept of Paediatrics, MKCG MCH, Berhampur, ODISHA \\ ${ }^{2}$ JR-2, Dept of Paediatrics, MKCG MCH, Berhampur, ODISHA
}

\begin{abstract}
Kawasaki disease is an acute, self-limited vasculitis of unknown aetiology that occurs predominantly in infants and children mostly below 5 years. It is considered the leading cause of acquired heart disease in children in developed countries. Diagnosis is mostly based on clinical features. Atypical Kawasaki diseases are patients who do not meet all the requisite criteria for diagnosis. Treatment includes high dose IVIG and aspirin. Most dreaded complication is coronary artery aneurysm (CAA). CAA occurs in 25-35\% Of untreated cases and can occur in $<5 \%$ cases treated with IVIG. A second dose of IVIG is given if the patient does not improve. Over the last few years, several newer treatment option as second and third line have been explored.

Here we are going to report 3 cases of Kawasaki disease with varied presentation admitted to PIPD $M K C G M C H$, in the month of April i.e. peak of Covid 19 era.

Keywords: Kawasaki, vasculitis, IVIG, aspirin, coronary artery aneurysm.
\end{abstract}

\section{Introduction}

Kawasaki disease (KD) is an acute, self-limiting systemic vasculitis affecting mostly medium vessels $^{[1]}$. First case was encountered in Japan by Dr. Tomisaku Kawasaki in January $1961^{[2]}$. Age group affected is mostly children below 5 years. Multiple theories have been proposed for the pathophysiology of the condition but the etiology of KD remains poorly understood. Diagnosis is mostly clinical. Kawasaki disease is treated with intravenous immunoglobulin (IVIG) and high dose aspirin. If not treated early with high-IVIG, 1 in 5 children develop coronary artery aneurysms; this risk is reduced 5-fold if IVIG is administered within 10 days of fever onset. Coronary artery aneurysm (CAA) evolve dynamically over time, usually reaching a peak dimension by 6 weeks after illness onset ${ }^{[3]}$. Timely diagnosis and early treatment will lead to better prognosis and minimize associated complications.

Here we present three cases of KD admitted to our department in the month of April.

\section{Case Study}

\section{Case-1 (Typical KD)}

Patient XXX, 18 months Mch product of nonconsanguineous marriage from lower middle socioeconomic status brought to our hospital with complaints of high grade fever for 7 days, redness of lips and tongue and redness of eyes for 7 days. No associated history of loose stool, burning micturition or eye discharge was present.

On examination child was irritable. Vitalstemperature $39^{\circ} \mathrm{C}, \mathrm{HR}-120, \mathrm{RR}-24$, Spo2- $99 \%$. 
Head to toe examination showed bilateral non purulent conjunctivitis, red fissured lips with strawberry tongue, unilateral cervical lymphadenopathy, swelling of hands and feet. Systemic examination was within normal limits.

Laboratory investigation revealed neutrophilic leucocytosis and thrombocytosis, CRP +ve, ESR$150 \mathrm{~mm}$. Pt was clinically diagnosed as a case of KD and treated with IVIG and aspirin. 2D ECHO was done and found to be normal. Child improved within 48 hours. Pt was discharged with oral aspirin advised for follow up and repeat 2D echo

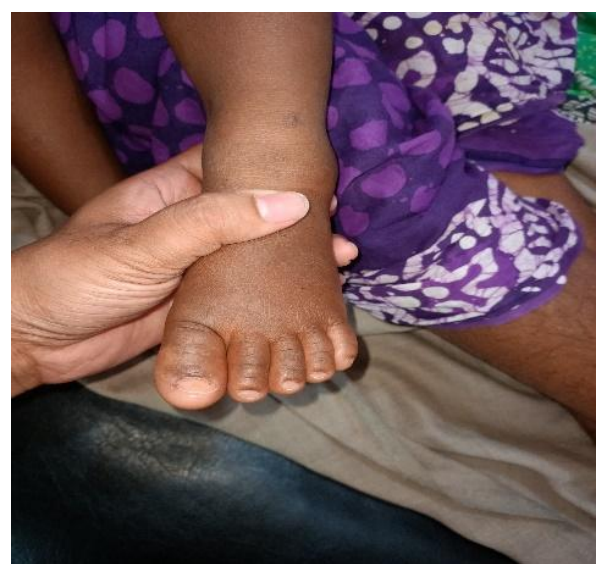

Figure 1 Edema of Foot

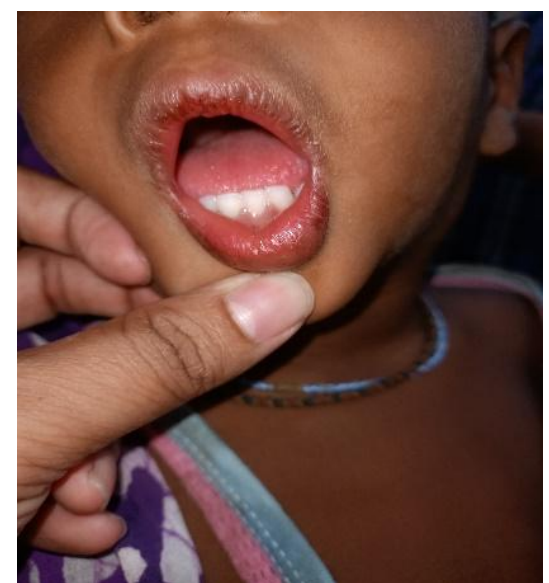

Figure 2 Red Lips \& Strawberry Tongue

\section{Case-2 (Atypical KD)}

Patient YYY, 9 months male child came with complaints of high grade fever for 8 days, perianal peeling of skin -3 days. History of rash on day 1 of fever which subsided. There was no history of loose stool or vomiting or cough or cold or eye discharge.
On examination child was found to be irritable with fever temperature of 39.2 degree Celsius, eyes were congested and non-purulent and perianal excoriation was found (Fink Sign). Systemic examination was within normal limits. Laboratory investigation revealed WBC- 18000, Hb- 7.5 gm, TPC- 3.5 lakh. CRP +ve, ESR$130 \mathrm{~mm}$.

Pt was started on empirical iv ceftriaxone

On day 3 of examination child developed tender periungual oedema and oedema of dorsum of hands \& feet. Repeat CBC revealed TPC of 5.5 lakhs. A diagnosis of atypical KD was made and patient was started with IVIG $2 \mathrm{~g} / \mathrm{kg}$ and aspirin orally. Child improved within 3 days. 2D ECHO was done and found to be normal. Child was discharged with oral aspirin for 6 weeks with advice for follow up along with 2D ECHO.

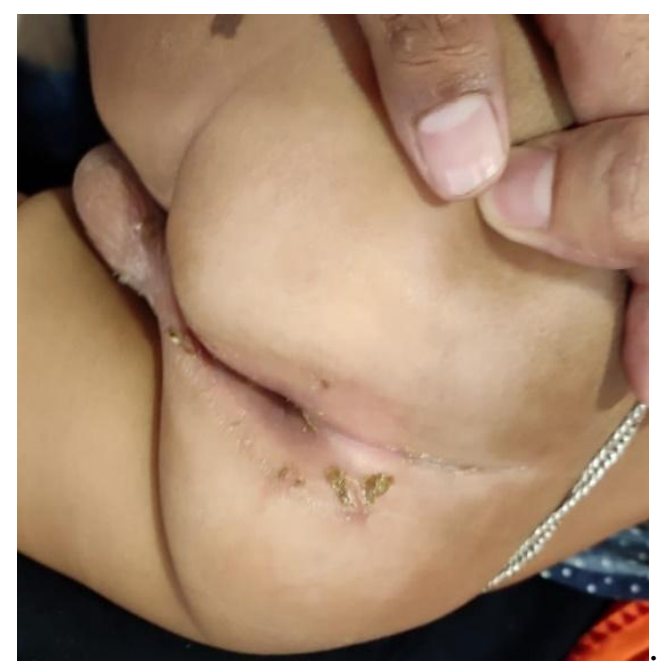

Figure 3 Perianal Excoriation

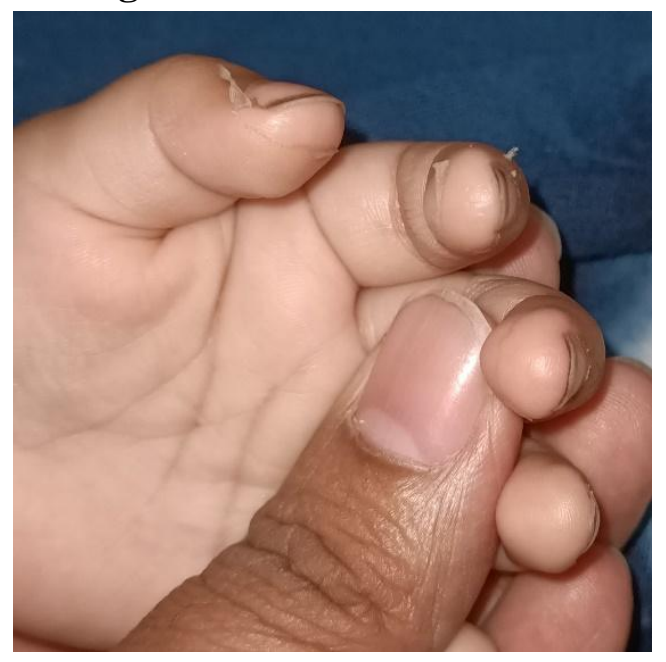

Figure 4 Periungual Peeling of Skin 


\section{Case-3 (Late Onset KD)}

Patient ZZZ, 9 yrs, female child came with complaints of high grade fever for 7 days, pain abdomen- 4 days, pain and swelling of hand and feet -4 days

History of swelling on left side of neck 6 days prior to admission now reduced in size. No history of loose stools or burning micturition.

On examination child was conscious, oriented. HR - 90, RR- 18, Spo2- 95\%, temp- 39 degree Celsius. On head to toe examination found to have bilateral non-purulent conjunctivitis, left cervical lymphadenopathy $(>1.5 \mathrm{~cm})$, strawberry tongue with red lips, swelling and tenderness with restricted movement of hands and feet. Rashes were noticed over the extensor surface of both legs and perianal excoriation was also seen.

Systemic examination was within normal limit.

On investigation found to have WBC-20800, $\mathrm{Hb}-$ 11.0 gm, TPC- 2.6 lakh, ASO- negative, CRPNegative, urine R\&M- pus cell 8-10/ HPF, albumin 2+, ESR-140, 2D echo - normal

Diagnosis of KD (Late onset) was made an IVIG $2 \mathrm{~g} / \mathrm{kg}$ and aspirin was given. Pt improved and was discharged with advice for follow up.

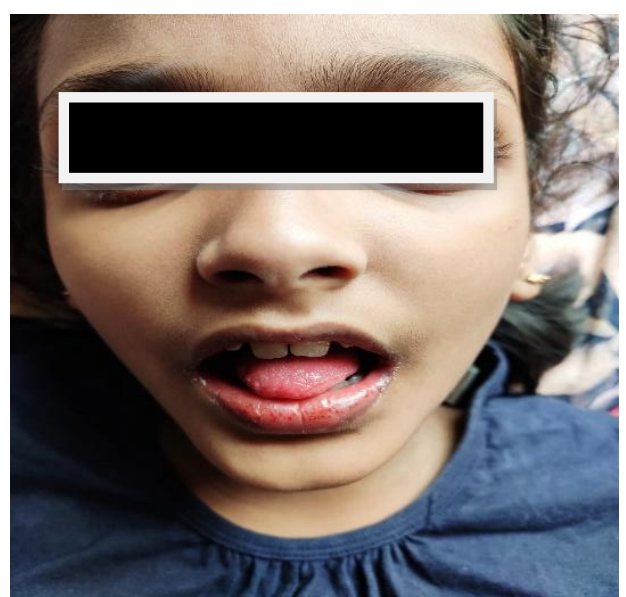

Figure 5 Red Congested Eyes, Red Lips with Strawberry Tongue

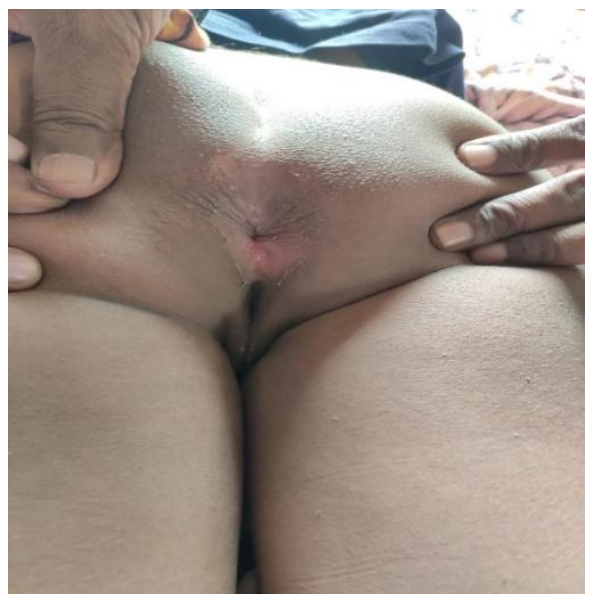

Figure 6 Perianal Excoriation

\section{Discussion}

Kawasaki disease is an acute febrile systemic vasculitis that was first described by Kawasaki et al. in $1974 .{ }^{[4]}$ It is a common pediatric vasculitis disorder with the annual incidence being in the range of $60-150 / 100,000$ in children below 5 years of age ${ }^{[5]} \mathrm{KD}$ occurs worldwide affecting children of all races, although Asians are believed to be at highest risk. The male-to-female ratio is $1.5: 1.0^{[6]}$

It is believed to be caused by an infectious agent in an immunologically susceptible individual, but the causative agent remains elusive. Some of the infectious agents proposed are parvovirus, Staphylococcus aureus, Epstein - Barr virus, chlamydia and mycobacteria. Onouchi et al., had suggested that a common infectious agent that triggers the clinically apparent disease in certain genetically predisposed individuals, particularly Asians, causes KD. ${ }^{[7]}$

The course of $\mathrm{KD}$ can be divided into three clinical phases: Acute, subacute and convalescent. $^{[8]}$

1. Acute phase:- lasts for 7-10 days characterised by fever, rash, unilateral cervical lymphadenopathy, conjunctival congestion, swelling ad erythema of hands and feet. It ends with resolution of fever.

2. Sub-acutephase: associated with desquamation, thrombocytosis, development of CAA, and highest risk of sudden death in 
pts who develop aneurysm. Lasts for around 3 weeks after acute phase.

3. Convalescent phase- begins when all clinical features disappeared and continues until ESR becomes normal typically around 6-8 weeks after onset of illness.

$\mathrm{KD}$ is a clinical diagnosis based on the characteristic history and physical findings.[8] The diagnosis of classic KD requires fever of at least 5 days duration and the presence of four of the following:

1. Changes in extremities, e.g., erythema, edema, and desquamation. Desquamation of the fingers and toes begins in the periungual region, may involve the palms and soles, and is usually observed 1-2 weeks after the onset of fever

2. Bilateral non-purulent bulbar conjunctivitis

3. Polymorphous rash (not vesicular)

4. Cervical lymphadenopathy (usually $>1.5 \mathrm{~cm}$ and unilateral; the least common of all clinical features, occurring in approximately $40 \%$ )

5. Changes in the lips and oral cavity (e.g., pharyngeal erythema, dry/fissured or swollen lips, strawberry tongue).

Not all patients with KD have symptoms that meet the classic diagnostic criteria. Children with $\mathrm{KD}$ exhibiting fever and fewer than four of the other characteristic symptoms, so-called atypical or incomplete KD. Supplementary laboratory criteria for incomplete KD are

Fever of $>5$ days associated with CRP - $3.0 \mathrm{mg} / \mathrm{dL}$ and/or ESR- $40 \mathrm{~mm}$ with the following 3 or more criteria:

- Anemia for age

- Albumin $\leq 3 \mathrm{gm} / \mathrm{dl}$

- Elevation of alanine aminotransferase

- Platelets after $7 \mathrm{~d} \geq 450,000 / \mathrm{mm}^{3}$

- White blood cell count $\geq 15,000 / \mathrm{mm}^{3}$

- Urine $\geq 10$ white blood cells/high-power field

OR

Positive Echocardiogram
The differential diagnosis includes Toxic shock syndrome (streptococcal and staphylococcal), staphylococcal scalded skin syndrome, scarlet fever, and infection with enterovirus, adenovirus, measles, parvovirus, EBV, CMV, mycoplasma pneumoniae $^{[9]}$

Cardiovascular manifestations can be prominent in the acute phase of the illness and are the leading cause of morbidity and mortality in children with untreated KD. Abnormalities may include diffuse ectasia or coronary aneurysms. Cardiac complications other than coronary arterial abnormalities include cardiac tamponade, cardiac failure, myocarditis, and pericarditis. ${ }^{[10]}$

Echocardiograms and angiograms obtained in long-term follow-up studies indicate that coronary aneurysms resolve within five to 18 months in approximately $50 \%$ of patients. ${ }^{[11]}$

The medical management of KD involves the use of gamma globulin and aspirin as antiinflammatory agents. Other like oral steroids, statins and long-term anticoagulation are also proposed as $2^{\text {nd }}$ line management. ${ }^{[12]}$ Periodic check-up and counselling for cardiovascular risk factors is recommended for all children who have KD.

In our case series, first case presented with typical symptoms and met all clinical criteria, diagnosed as $\mathrm{KD}$ and received IVIG and aspirin and improved within 24 hours.

$2^{\text {nd }}$ case presented with fever and perianal excoriation. Lab investigation revealed thrombocytosis, high ESR and +ve CRP. We suspected this to be a case of $\mathrm{KD}$. On day 3 periungual peeling was seen and thrombocytosis increased which further strengthened our diagnosis. It was diagnosed as atypical KD. Treated with IVIG and aspirin. Pt improved and got discharged.

$3^{\text {rd }}$ case presented with features of KD and met clinical criteria of KD though the age of the patient was not the typical age. It is rare to find KD in children beyond 8 years. Child improved with IVIG and aspirin. 


\section{Conclusion}

$\mathrm{KD}$ is a systemic vasculitis, self-limiting usually seen in children below 5 years. Diagnosis is mainly by clinical criteria. Atypical KD do not meet all the clinical criteria but warrants treatment. Most dreaded complication is coronary artery aneurysm (CAA). CAA occurs in around 25 $\%$ of untreated cases. It can also occur in adolescents too. High index of suspicion is required for the diagnosis. If treated within 10 days of onset CAA can be prevented.

For last 2 decades we have not seen so much so 3 cases in a month. But during this covid 19 pandemic why we got 3 cases in a month of APRIL the exact answer is not known. Getting more such cases in coming days and more understanding of corona outbreak will say whether it is coincidental or covid 19 triggered.

\section{References}

1. Ozen S, Ruperto N, Dillon MJ, et al. EULAR/PReS endorsed consensus criteria for the classification of childhood vasculitides. Ann Rheum Dis. 2006; 65: 936-41. [PMC free article] [PubMed] [Google Scholar]

2. Kawasaki T. Acute febrile mucocutaneous syndrome with lymphoid involvement with specific desquamation of the fingers and toes in children. Arerugi [Allergy] 1967;16:178-222. [PubMed]

3. Newburger JW, Takahashi M, Gerber MA, et al. Diagnosis, treatment, and long-term management of Kawasaki disease: a statement for health professionals from the Committee on Rheumatic Fever, Endocarditis, and Kawasaki Disease, Council on Cardiovascular Disease in the Young, American Heart Association. Pediatrics. 2004;114:1708-33. [PubMed] [Google Scholar]

4. Kawasaki T, Kosaki F, Okawa S, Shigematsu I, Yanagawa H. A new infantile acute febrile mucocutaneous lymph node syndrome (MLNS) prevailing in Japan. Pediatrics. 1974;54(3):271-6. Epub 1974/09/01. [Links]

5. Laupland KB, Dele Davis $\mathrm{H}$. Epidemiology, etiology, and management of Kawasaki disease: state of art. Pediatr Cardiol. 1999;20:177-83.

6. Singh S, Kawasaki T. Kawasaki disease An Indian perspective. Indian Pediatr 2009;46:563-71.

7. Yeung RS. Kawasaki disease: Update on pathogenesis. Curr Opin Rheumatol 2010; 22:551-60.

8. JCS Joint Working Group. Guidelines for diagnosis and management of cardiovascular sequelae in Kawasaki disease (JCS 2013). Circ J 2014;78:252162. [Crossref] [PubMed]

9. Cho EY, Eun BW, Kim NH, et al. Association between Kawasaki disease and acute respiratory viral infections. Korean J Pediatr 2009;52:1241-8. [Crossref]

10. Chang FY, Hwang B, Chen SJ, et al. Characteristics of Kawasaki disease in infants younger than six months of age. Pediatric Infect Dis J 2006;25:241-4. [Crossref] [PubMed]

11. Salgado AP, Ashouri N, Berry EK, et al. High Risk of Coronary Artery Aneurysms in Infants Younger than 6 Months of Age with Kawasaki Disease. J Pediatr 2017; 185:112-116.e1. [Crossref]

12. Crindle BW, Rowley AH, Newburger JW, et al. Diagnosis, Treatment, and LongTerm Management of Kawasaki Disease: A Scientific Statement for Health Professionals From the American Heart Association. Circulation 2017;135:e92799. [Crossref]. 